\title{
DEFICIÊNCIA HÍDRICA E USO DE GRANULADOS EM LAVOURA CAFEEIRA IRRIGADA POR GOTEJAMENTO
}

\author{
André Luís Teixeira Fernandes ${ }^{1}$, Roberto Santinato ${ }^{2}$, Ricardo Lessi ${ }^{3}$, Antonio Yamada ${ }^{4}$ \& \\ Vantuir A. Silva ${ }^{5}$
}

\begin{abstract}
RESUMO
Com o objetivo de se estudar o desenvolvimento vegetativo e produtivo de uma lavoura de café nas condições de Planaltina de Goiás, GO, instalou-se um experimento numa lavoura de café Mundo Novo, recepada, onde foram comparados diferentes períodos de déficit hídrico (DH) e aplicação de variados produtos granulados no solo. Com avaliações de produção para os anos de 1995, 1996 e 1997, observou-se que, sob irrigação total e sem déficit hídrico, a cultura apresentou a maior produtividade, com acréscimos de até $100 \%$ quando comparada com o tratamento sem irrigação. Quanto aos granulados, independentemente do tratamento de irrigação, verificou-se melhor desempenho da associação triadimenol + dissulfoton, com aumentos de produtividade de 20 a $25 \%$.

Palavras-chave: Coffea arabica L., deficiência hídrica, granulados de solo

\section{WATER STRESS EFFECT AND USE OF GRANULATED PRODUCTS IN COFFEE CROP IRRIGATED BY THE DRIP SYSTEM}

ABSTRACT

In order to study the vegetative and produtive development of irrigated coffee of the "Mundo Novo' variety, an experiment in Planaltina de Goiás, GO was installed. Different periods of water deficit and application of different granulated products were compared. Crop evaluation performed for 3 harvests $(1995,1996$ and 1997) showed that irrigated plants (with no water deficit) produced $100 \%$ more than those without irrigation. As for soil granulate, triadimenol + dissulfoton showed a 20 to $25 \%$ increase in production regardless of irrigation.
\end{abstract}

Key words: Coffea arabica L., water deficit, soil granulated products

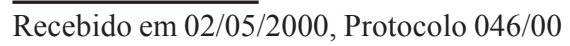

${ }^{1}$ Eng. Agrônomo, Ms. Irrigação e Drenagem, Doutorando FEAGRI/UNICAMP, Professor Universidade de Uberaba, Instituto de Ciências e Tecnologia do Ambiente, Av. Nenê Sabino, 1801 - Bairro Universitário, CEP 38055 - 500, Uberaba, MG. Fone: (0xx34) 312 0187, Fax: (0xx34) 321 6734. E-mail: andre.fernandes@uniube.br

${ }^{2}$ Eng. Agrônomo, Pesquisador do Ministério da Agricultura / PROCAFÉ, Fazenda do Café, Av. Heitor Penteado, s/n, CEP 13100 - 000, Campinas, SP. Fone: (0xx19) 2560200

${ }^{3}$ Eng. Agrônomo, BAYER S.A. Proteção das Plantas/Marketing; Rua Domingos Jorge, 1000 - Bairro Socorro, CEP 04779 - 900 , São Paulo, SP. Fone: (0xx17) 975-2117

${ }^{4}$ Administração Grupo Yamada, Fazenda Grupo Yamada, CEP 74750 - 000, Planaltina de Goiás, GO

${ }^{5}$ Aluno Centro Regional Universitário Espírito Santo do Pinhal, Rua José OlímpioTeixeira, 80, CEP 13990 - 000, Espírito Santo do Pinhal, SP 


\section{INTRODUÇÃO}

A cultura do cafeeiro (Coffea arabica L.) é de relevada importância na agricultura e na economia brasileira, desde a sua introdução no Brasil. Inicialmente, a cafeicultura se desenvolveu em regiões consideradas aptas à cultura, no que diz respeito às necessidades hídricas mas, com a introdução da cultura em regiões consideradas marginais em termos de disponibilidade hídrica, tornou-se necessária a adoção de novas tecnologias de cultivo, em especial a irrigação.

O principal objetivo da irrigação, segundo Gomide (1998) é fornecer quantidade adequada de água às plantas, para evitar o déficit hídrico, que pode afetar, tanto em quantidade como em qualidade, a produção da cultura. Sempre que a água proveniente da precipitação não for suficiente para atender à demanda hídrica das plantas e a disponibilidade de água do solo for esgotada em níveis que possam provocar redução significativa de produtividade, haverá sempre necessidade de se suprir as carências hídricas das culturas, com a aplicação de água de irrigação.

O uso da irrigação tem proporcionado a produção de café em regiões com precipitação pluvial bastante aquém das suas necessidades, tendo-se verificado aumentos consideráveis de produção na qualidade da bebida obtida com a lavoura irrigada. Nas regiões consideradas marginais à cafeicultura, muitos plantios efetuados sem o suprimento artificial de água foram seriamente prejudicados.

Vários autores verificaram o efeito positivo da irrigação no crescimento (Matiello \& Dantas, 1987; Zanini et al., 1994) e na produção do cafeeiro (Barreto et al., 1972; Njoroge, 1989; Reis et al., 1990). Araújo (1982) verificou que a irrigação, além de maior produtividade, possibilitou um produto de melhor tipo e bebida porém, por se tratar de técnica relativamente nova dentro da tecnologia de produção de café, tornam-se necessários estudos que visem proporcionar ao cafeicultor irrigante a garantia da aplicação de água no momento adequado e em quantidades suficientes.

Uma das alternativas mais viáveis para os agricultores, pela sua simplicidade e relativa eficiência, é a utilização do balanço hídrico climatológico. Camargo (1989) observa que o modelo de quantificação de rega climático fenológico é baseado no balanço contábil entre a demanda de água (fundamentada na evapotranspiração potencial) e a disponibilidade hídrica no solo (baseada na capacidade de armazenamento de água facilmente disponível na zona radicular) além do suprimento de água fornecido pela irrigação, ou pela precipitação pluvial, medida em pluviômetros, junto à cultura. As únicas variáveis que o cafeicultor necessita determinar, são: a precipitação, obtida em pluviômetros comuns; a temperatura média do período e o coeficiente de cultura para correção da evapotranspiração de referência, em função da porcentagem de cobertura do solo (Camargo, 1987). Segundo Pereira et al. (1997) o balanço hídrico se constitui no sistema contábil de monitoramento da água no solo, onde são fornecidos dados de precipitação e de demanda atmosférica para serem estimados valores da evapotranspiração real, da deficiência, do excedente e do armazenamento de água no solo. Trata-se de um método bastante simples de manejo da irrigação, possível de ser utilizado pelos cafeicultores.
$\mathrm{O}$ uso de granulados de solo, principalmente fungicidas e inseticidas sistêmicos, na cultura do cafeeiro, tem crescido bastante nos últimos anos, na medida em que combate alguns dos principais problemas de pragas e doenças da cultura, como bicho-mineiro e ferrugem. Para uma aplicação eficiente desses produtos, alguns cuidados devem ser tomados, como: aplicá-los com o solo úmido; aplicá-los sob a "saia" do cafeeiro no local de maior concentração radicular; não aplicá-los em solo compactado; seguir as recomendações de nutrição/adubação adequadas; aplicá-los sempre no início das chuvas e evitar o uso de grade, roçadora etc.

Em lavouras irrigadas em áreas de deficiência hídrica acentuada ( $\mathrm{DH}>150 \mathrm{~mm} \mathrm{ano}^{-1}$ ) independentemente do sistema de irrigação adotado, tem-se observado que, na prática, o uso de granulados no solo, notadamente a associação inseticidafungicida sistêmico, confere maior vigor vegetativo e produtivo à cultura, embora esses produtos não apresentem nenhum elemento fertilizante. Esta situação é verificada mesmo quando a irrigação é deficiente, ou seja, a lâmina aplicada é inferior à necessidade real calculada pelo balanço hídrico climatológico (Santinato et al., 1996). Em experimento realizado em Manhumirim, MG, Barros et al. (1999) concluíram após 9 safras aplicando diferentes combinações de triadimenol e dissulfoton, que o uso da associação triadimenol + dissulfoton, desde o plantio, além de manter a ferrugem controlada evita a queda acentuada de folhas, mantendo a cultura em pleno vigor vegetativo e proporcionando um incremento significativo na média da produção, podendo chegar a até $59 \%$ em relação à testemunha que não recebeu produtos granulados. Matiello et al. (1999) explicam que o aumento de produção da lavoura cafeeira com a aplicação de produtos granulados no solo ocorre devido ao efeito hormonal deste produto graças, principalmente, ao seu ativo fungicida, que proporciona a melhoria do sistema radicular da cultura.

Com o objetivo de se estudar a recuperação de lavoura depauperada nas condições de Planaltina de Goiás, GO, conduziu-se um experimento para efeito de comparação de diferentes períodos de defíciência hídrica, como a utilização dos produtos granulados de solo mais utilizados na cafeicultura, sendo as avaliações feitas para os anos de 1995, 1996 e 1997. A região é classificada apta para o cultivo do café, mas com irrigação obrigatória, segundo Santinato et al. (1996) devido aos seus altos valores de deficiência hídrica anual.

\section{MATERIAL E MÉTODOS}

O experimento foi instalado em Planaltina, GO, numa lavoura de café Mundo Novo 379/19, com 8 anos de idade, recepada em 1993, com espaçamento de 4,2 x 1,0 m, em um Latossolo Vermelho-Escuro, com declive de 4 a $5 \%$ e altitude de $850 \mathrm{~m}$. As características físico-hídricas do solo podem ser observadas na Tabela 1.

O sistema de irrigação utilizado foi o gotejamento, com emissores autocompensantes, com vazão de $4,0 \mathrm{~L} \mathrm{~h}^{-1}$, sendo o manejo realizado por meio do balanço hídrico climatológico, com utilização de observações de temperatura média do $\operatorname{ar}\left({ }^{\circ} \mathrm{C}\right)$ e precipitação total (mm de chuva) ambas medidas às $9 \mathrm{~h}$ da manhã. 
Tabela 1. Características físico hídricas do solo do experimento

\begin{tabular}{lc}
\hline Características & Valor \\
\hline Areia & $68 \%$ \\
Argila & $32 \%$ \\
Ponto de murcha permanente & $0,182 \mathrm{~cm}^{3} \mathrm{~cm}^{-3}$ \\
Capacidade de campo & $0,261 \mathrm{~cm}^{3} \mathrm{~cm}^{-3}$ \\
Água disponível & $0,079 \mathrm{~cm}^{3} \mathrm{~cm}^{-3}$ \\
Densidade aparente & $1,391 \mathrm{~kg} \mathrm{dm}^{-3}$ \\
\hline
\end{tabular}

O cálculo da evapotranspiração foi obtido a partir do Método de Camargo, introduzido por Camargo \& Camargo (1983) e é uma adaptação do proposto por Thornthwaite (1954) substituindo a correção da duração do dia pela radiação solar no topo da atmosfera $\left(Q_{\mathrm{o}}\right)$. A estimativa da evapotranspiração $\left(\mathrm{ET}_{\mathrm{o}}\right), \mathrm{em} \mathrm{mm} \mathrm{d}^{-1}$, por esse método, se baseia na energia da radiação solar incidente em superfície horizontal acima da atmosfera e na temperatura média do ar, segundo a expressão geral:

$$
\mathrm{ET}_{\mathrm{o}}=\mathrm{T}_{\mathrm{a}} \cdot \mathrm{d} \cdot \mathrm{f}
$$

em que:

Tabela 2. Valores de $\mathrm{f}$ da fórmula de Camargo para latitudes compreendidas entre $17 \mathrm{e} 25^{\circ} \mathrm{S}\left(\mathrm{mm} \mathrm{d}^{-1}\right)$

\begin{tabular}{|c|c|c|c|c|c|c|c|c|c|c|}
\hline \multirow{2}{*}{ Mês } & \multirow{2}{*}{ Decêndio } & \multicolumn{9}{|c|}{ Latitudes } \\
\hline & & $17^{\circ}$ & $18^{\circ}$ & $19^{\circ}$ & $20^{\circ}$ & $21^{\circ}$ & $22^{\circ}$ & $23^{\circ}$ & $24^{\circ}$ & $25^{\circ}$ \\
\hline \multirow{3}{*}{ Jan } & 1 & 0,17 & 0,17 & 0,17 & 0,17 & 0,17 & 0,17 & 0,17 & 0,17 & 0,17 \\
\hline & 2 & 0,17 & 0,17 & 0,17 & 0,17 & 0,17 & 0,17 & 0,17 & 0,17 & 0,17 \\
\hline & 3 & 0,17 & 0,17 & 0,17 & 0,17 & 0,17 & 0,17 & 0,17 & 0,17 & 0,17 \\
\hline \multirow{3}{*}{$\mathrm{Fev}$} & 1 & 0,16 & 0,16 & 0,16 & 0,16 & 0,16 & 0,16 & 0,16 & 0,16 & 0,16 \\
\hline & 2 & 0,16 & 0,16 & 0,16 & 0,16 & 0,16 & 0,16 & 0,16 & 0,16 & 0,16 \\
\hline & 3 & 0,16 & 0,16 & 0,16 & 0,16 & 0,16 & 0,16 & 0,16 & 0,16 & 0,16 \\
\hline \multirow{3}{*}{ Mar } & 1 & 0,15 & 0,15 & 0,15 & 0,15 & 0,15 & 0,15 & 0,15 & 0,15 & 0,15 \\
\hline & 2 & 0,15 & 0,15 & 0,15 & 0,15 & 0,15 & 0,15 & 0,15 & 0,15 & 0,15 \\
\hline & 3 & 0,14 & 0,14 & 0,14 & 0,14 & 0,14 & 0,14 & 0,14 & 0,14 & 0,14 \\
\hline \multirow{3}{*}{ Abr } & 1 & 0,14 & 0,14 & 0,14 & 0,14 & 0,14 & 0,14 & 0,14 & 0,14 & 0,14 \\
\hline & 2 & 0,13 & 0,13 & 0,13 & 0,13 & 0,13 & 0,13 & 0,13 & 0,13 & 0,13 \\
\hline & 3 & 0,12 & 0,12 & 0,12 & 0,12 & 0,12 & 0,12 & 0,12 & 0,12 & 0,12 \\
\hline \multirow{3}{*}{ Mai } & 1 & 0,12 & 0,12 & 0,12 & 0,12 & 0,12 & 0,12 & 0,12 & 0,12 & 0,12 \\
\hline & 2 & 0,11 & 0,11 & 0,11 & 0,11 & 0,11 & 0,11 & 0,11 & 0,11 & 0,11 \\
\hline & 3 & 0,11 & 0,11 & 0,11 & 0,11 & 0,11 & 0,11 & 0,11 & 0,11 & 0,11 \\
\hline \multirow{3}{*}{ Jun } & 1 & 0,10 & 0,10 & 0,10 & 0,10 & 0,10 & 0,10 & 0,10 & 0,10 & 0,10 \\
\hline & 2 & 0,10 & 0,10 & 0,10 & 0,10 & 0,10 & 0,10 & 0,10 & 0,10 & 0,10 \\
\hline & 3 & 0,10 & 0,10 & 0,10 & 0,10 & 0,10 & 0,10 & 0,10 & 0,10 & 0,10 \\
\hline \multirow{3}{*}{ Jul } & 1 & 0,10 & 0,10 & 0,10 & 0,10 & 0,10 & 0,09 & 0,09 & 0,09 & 0,09 \\
\hline & 2 & 0,11 & 0,10 & 0,10 & 0,10 & 0,10 & 0,10 & 0,09 & 0,09 & 0,09 \\
\hline & 3 & 0,11 & 0,11 & 0,11 & 0,10 & 0,10 & 0,10 & 0,10 & 0,10 & 0,09 \\
\hline \multirow{3}{*}{ Ago } & 1 & 0,11 & 0,11 & 0,11 & 0,11 & 0,11 & 0,11 & 0,10 & 0,10 & 0,11 \\
\hline & 2 & 0,12 & 0,12 & 0,12 & 0,12 & 0,11 & 0,11 & 0,11 & 0,11 & 0,11 \\
\hline & 3 & 0,13 & 0,13 & 0,13 & 0,12 & 0,12 & 0,12 & 0,12 & 0,11 & 0,11 \\
\hline \multirow{3}{*}{ Set } & 1 & 0,13 & 0,13 & 0,13 & 0,13 & 0,13 & 0,13 & 0,12 & 0,12 & 0,12 \\
\hline & 2 & 0,14 & 0,14 & 0,14 & 0,14 & 0,13 & 0,13 & 0,13 & 0,13 & 0,13 \\
\hline & 3 & 0,14 & 0,14 & 0,14 & 0,14 & 0,14 & 0,14 & 0,14 & 0,14 & 0,14 \\
\hline \multirow{3}{*}{ Out } & 1 & 0,15 & 0,15 & 0,15 & 0,15 & 0,15 & 0,15 & 0,15 & 0,15 & 0,14 \\
\hline & 2 & 0,15 & 0,15 & 0,15 & 0,15 & 0,15 & 0,15 & 0,15 & 0,15 & 0,15 \\
\hline & 3 & 0,16 & 0,16 & 0,16 & 0,16 & 0,16 & 0,16 & 0,16 & 0,16 & 0,16 \\
\hline \multirow{3}{*}{ Nov } & 1 & 0,16 & 0,16 & 0,16 & 0,16 & 0,16 & 0,16 & 0,16 & 0,16 & 0,16 \\
\hline & 2 & 0,16 & 0,16 & 0,16 & 0,16 & 0,16 & 0,17 & 0,17 & 0,17 & 0,17 \\
\hline & 3 & 0,17 & 0,17 & 0,17 & 0,17 & 0,17 & 0,17 & 0,17 & 0,17 & 0,17 \\
\hline \multirow{3}{*}{ Dez } & 1 & 0,17 & 0,17 & 0,17 & 0,17 & 0,17 & 0,17 & 0,17 & 0,17 & 0,17 \\
\hline & 2 & 0,17 & 0,17 & 0,17 & 0,17 & 0,17 & 0,17 & 0,17 & 0,17 & 0,17 \\
\hline & 3 & 0,17 & 0,17 & 0,17 & 0,17 & 0,17 & 0,17 & 0,17 & 0,17 & 0,17 \\
\hline
\end{tabular}

$\mathrm{T}_{\mathrm{a}} \quad$ - temperatura média do ar, em graus Celsius $\left({ }^{\circ} \mathrm{C}\right)$.

d - número de dias do período considerado

f - resultado do produto entre $\mathrm{Q}_{\mathrm{o}}$ (radiação solar no topo da atmosfera, em $\mathrm{mm} \mathrm{d}^{-1}$ e a constante de Camargo (Tabela 2).

Para a determinação da necessidade hídrica da cultura utilizou-se um coeficiente cultural, $\mathrm{K}_{\mathrm{c}}$ (Tabela 2) que, multiplicado pela $\mathrm{ET}_{0}$ obtida pelo Método de Camargo, resultou em valores de evapotranspiração da cultura $\left(\mathrm{ET}_{\mathrm{c}}\right)$.

O delineamento experimental foi o inteiramente casualizado, com 27 tratamentos (9 de irrigação e 3 de granulados) e 3 repetições, com parcelas definidas por 3 linhas de 15 plantas, consideradas úteis as 10 plantas da linha central de cada parcela. Todas as parcelas contaram com controle individualizado, proporcionado pela instalação de registros de esferas no início de cada parcela.

Os tratamentos de irrigação utilizados foram: a) testemunha (sem irrigação - não houve fornecimento de água à cultura em nenhuma fase do seu desenvolvimento); b) deficiência hídrica $(\mathrm{DH})=0$ (as parcelas foram irrigadas durante o ano, sem 
Tabela 3. Coeficiente de cultura $\left(\mathrm{K}_{\mathrm{c}}\right)$ do café (Coffea arabica L.)

\begin{tabular}{llcc}
\hline $\begin{array}{l}\text { Idade } \\
\text { (anos) }\end{array}$ & $\begin{array}{l}\text { Espaçamento }-\mathrm{m} \\
\text { Rua x Plantas }\end{array}$ & No. de plantas ha & $\mathrm{K}_{\mathrm{c}}$ \\
\hline Maior que & a) $>3,0 \times>1,0$ & 2,500 & 1,0 \\
3 & b) $>3,0 \times 0,5$ a 1,0 & 3,333 & 1,2 \\
& c) 2 a $3 \times 0,5$ a 1,0 & 6,666 & 1,2 \\
De 1 a 3 & d) 1 a $2 \times 0,5$ a 1,0 & 13,333 & 1,3 \\
& a) $>3,0 \times>1,0$ & 2,500 & 0,8 \\
& b) $>3,0 \times 0,5$ a 1,0 & 3,333 & 0,9 \\
& c) 2 a $3 \times 0,5$ a 1,0 & 6,666 & 1,0 \\
De 0 a 1 & d) 1 a $2 \times 0,5$ a 1,0 & 13,333 & 1,1 \\
& a) $>3,0 \times>1,0$ & 2,500 & 0,6 \\
& b) $>3,0 \times 0,5$ a 1,0 & 3,333 & 0,7 \\
& c) 2 a $3 \times 0,5$ a 1,0 & 6,666 & 0,8 \\
d) 1 a $2 \times 0,5$ a 1,0 & 13,333 & 0,9 \\
\hline
\end{tabular}

Fonte: Santinato et al. (1996)

deficiência hídrica, de acordo com o balanço hídrico climatológico); c) $\mathrm{DH}=30$ dias (as parcelas foram irrigadas durante todo o seu desenvolvimento, exceto no mês de setembro); d) $\mathrm{DH}=60$ dias (as irrigações foram interrompidas nos meses de agosto e setembro); e) DH $=90$ dias (as irrigações foram interrompidas nos meses de julho, agosto e setembro); f) $\mathrm{DH}=120$ dias (as irrigações foram interrompidas no período de junho a setembro); g) DH $=150$ dias (as irrigações foram interrompidas no período de maio a setembro); h) $\mathrm{DH}=180$ dias (as irrigações foram interrompidas no período de abril a setembro) e i) $\mathrm{DH}=180$ dias (as irrigações foram interrompidas no período chuvoso, de outubro a março). Utilizou-se o método do balanço hídrico climatológico para determinação do momento e da quantidade de água a ser aplicada nas parcelas referentes ao tratamento de irrigação total. Nos outros tratamentos, com a adoção de déficits hídricos, a irrigação foi interrompida por um período de 30 a 180 dias, conforme já descrito.

Além do efeito da irrigação estudou-se, também, efeito de granulados de solo (fungicidas-inseticidas sistêmicos) na condução da lavoura, visto que, em observações práticas, a utilização desses produtos permite a obtenção de resultados satisfatórios. Os tratamentos foram: a) testemunha (sem granulados); b) Triadimenol + Dissulfoton (associação do fungicida sistêmico do grupo dos triazóis com o inseticida sistêmico organofosforado, classe toxicológica I - produto comercial Baysiston) na dosagem de $50 \mathrm{~kg} \mathrm{ha}^{-1} \mathrm{ano}^{-1}$; c) Triadimenol (fungicida sistêmico do grupo dos triazóis, classe toxicológica II - produto comercial Bayfidan GR) na dosagem de $15 \mathrm{~kg} \mathrm{ha}^{-1}$ ano $^{-1} \mathrm{e}$ Aldicarb (inseticida, acaricida e nematicida sistêmico do grupo dos carbamatos, classe toxicológica I produto comercial Temik) na dosagem de $20 \mathrm{~kg} \mathrm{ha}^{-1} \mathrm{ano}^{-1}$. O produto comercial Baysiston tem registro para café no controle da ferrugem do cafeeiro e também do bicho-mineiro, enquanto o Bayfidan o tem para o controle preventivo, curativo e erradicativo da ferrugem do cafeeiro, e o registro do produto Temik é para o controle do bicho-mineiro, nematóides e cigarras (Compêndio de defensivos agrícolas, 1990).

\section{RESULTADOS E DISCUSSÃO}

Durante o período do ensaio verificaram-se valores de deficiência hídrica anual de 197, 276 e 208 mm, nos anos de 1995, 1996 e 1997, respectivamente.
Na Tabela 4A, B e C, podem ser observados os dados de temperatura média do ar $\left({ }^{\circ} \mathrm{C}\right)$, irrigação $(\mathrm{mm})$, precipitação (mm) e evapotranspiração (mm) para os anos de 1995, $1996 \mathrm{e}$ 1997. A determinação da irrigação refere-se ao tratamento de irrigação total, ou sem déficit hídrico. Verifica-se que, em alguns períodos, a irrigação ultrapassou os valores de $\mathrm{P}-\mathrm{ET}_{\mathfrak{c}}$, devido à característica acentuadamente arenosa do solo, que culmina numa baixa capacidade de retenção de água do mesmo, conforme comprovam as características físicohídricas do solo.

Tabela 4. Temperatura média mensal, precipitação mensal, irrigação e evapotranspiração da cultura durante o período

\begin{tabular}{lrrrr}
\hline Mês & $\mathrm{T}\left({ }^{\circ} \mathrm{C}\right)$ & $\mathrm{P}(\mathrm{mm})$ & $\mathrm{I}(\mathrm{mm})$ & $\mathrm{ET}_{\mathrm{c}}(\mathrm{mm})$ \\
\hline A. 1995 & & & & \\
Janeiro & 25,8 & 348,0 & 29,0 & 138,0 \\
Fevereiro & 24,4 & 244,0 & 79,0 & 113,5 \\
Março & 25,5 & 184,0 & 0,0 & 122,8 \\
Abril & 24,6 & 103,0 & 21,0 & 99,3 \\
Maio & 23,3 & 27,0 & 90,0 & 96,9 \\
Junho & 20,6 & 0,0 & 152,0 & 64,5 \\
Julho & 21,5 & 0,0 & 137,0 & 72,1 \\
Agosto & 23,3 & 0,0 & 126,0 & 89,4 \\
Setembro & 24,4 & 0,0 & 163,0 & 104,3 \\
Outubro & 26,1 & 138,0 & 131,0 & 130,5 \\
Novembro & 24,4 & 298,0 & 12,0 & 121,9 \\
Dezembro & 24,8 & 287,0 & 44,0 & 131,6 \\
\hline Média/Total & 24,1 & 1629,0 & 984,0 & 1284,8 \\
\hline B. 1996 & & & & \\
Janeiro & 25,3 & 177,0 & 0,0 & 135,5 \\
Fevereiro & 25,5 & 55,0 & 149,0 & 119,0 \\
Março & 25,3 & 111,0 & 102,0 & 121,2 \\
Abril & 24,1 & 247,0 & 123,0 & 97,0 \\
Maio & 23,1 & 33,0 & 136,0 & 94,9 \\
Junho & 20,8 & 0,0 & 174,0 & 64,7 \\
Julho & 21,0 & 0,0 & 138,0 & 70,1 \\
Agosto & 22,4 & 0,0 & 155,0 & 85,7 \\
Setembro & 24,1 & 15,0 & 149,0 & 103,5 \\
Outubro & 25,8 & 98,0 & 95,0 & 127,7 \\
Novembro & 23,3 & 349,0 & 12,0 & 115,8 \\
Dezembro & 25,0 & 374,0 & 67,0 & 131,7 \\
\hline Média/Total & 23,8 & 1459,0 & 1300,0 & 1266,8 \\
\hline C. 1997 & & & & \\
Janeiro & 23,9 & 171,0 & 0,0 & 126,6 \\
Fevereiro & 24,8 & 196,0 & 84,0 & 115,4 \\
Março & 23,5 & 412,0 & 0,0 & 111,2 \\
Abril & 22,9 & 46,0 & 60,0 & 91,7 \\
Maio & 21,7 & 45,0 & 112,0 & 87,6 \\
Junho & 21,3 & 41,0 & 63,0 & 66,7 \\
Julho & 20,8 & 0,0 & 169,0 & 69,8 \\
Agosto & 23,1 & 0,0 & 153,0 & 88,7 \\
Setembro & 26,6 & 35,0 & 174,0 & 115,3 \\
Outubro & 25,6 & 130,0 & 68,0 & 126,4 \\
Novembro & 26,4 & 270,0 & 82,0 & 134,1 \\
Dezembro & 24,9 & 363,0 & 0,0 & 132,2 \\
\hline Média/Total & 23,8 & 1709,0 & 965,0 & 1265,7 \\
\hline & & & & \\
\hline
\end{tabular}

Em termos de produção, foram comparados isoladamente os tratamentos referentes à irrigação e ao uso de granulados de solo e, também, a associação irrigação x granulados (Tabela 5). Verificada a diferença entre os tratamentos, foi aplicado o teste de Tukey a 5\% de probabilidade, para comparação das médias (Tabela 6). 
Tabela 5. Análise de variância dos diferentes tratamentos

\begin{tabular}{lrrrr}
\hline Causa Variação & DF & \multicolumn{1}{c}{ SQ } & \multicolumn{1}{c}{ QM } & \multicolumn{1}{c}{ F } \\
\hline Irrigação & 8 & 3461,02 & 432,63 & 73,28 \\
Granulados & 12 & 290,72 & 145,36 & 24,62 \\
Irrig. x Gran. & 16 & 323,55 & 20,22 & 3,43 \\
Resíduo & 54 & 318,82 & 5,90 & \\
Total & 80 & 4394,10 & & \\
\hline
\end{tabular}

Tabela 6. Efeitos dos tratamentos de irrigação e utilização de produtos granulados na produção de café (em sacas de $60 \mathrm{~kg}$ beneficiadas por hectare) na região de Planaltina de Goiás, GO

\begin{tabular}{|c|c|c|c|c|c|}
\hline \multirow{2}{*}{ Tratamento } & \multirow{2}{*}{ Granulados } & \multicolumn{4}{|c|}{ Sacas de café beneficiadas por ha } \\
\hline & & 1995 & 1996 & 1997 & Média $^{*}$ \\
\hline \multirow{3}{*}{$\begin{array}{l}\mathrm{DH}=100 \% \\
\text { (sem irrigação) }\end{array}$} & S/Granul. & 20,9 & 15,2 & 27,7 & $21,3 \mathrm{e}$ \\
\hline & 50 Bays. & 22,8 & 22,8 & 30,0 & $25,2 \mathrm{de}$ \\
\hline & $15 \mathrm{~B}+20 \mathrm{~T}$ & 25,2 & 25,2 & 26,1 & $25,5 \mathrm{e}$ \\
\hline Média & & 23,0 & 21,1 & 27,9 & $24,0 \mathrm{e}$ \\
\hline \multirow[t]{3}{*}{$\mathrm{DH}=0$} & S/Granul. & 18,0 & 63,3 & 43,7 & $41,7 \mathrm{c}$ \\
\hline & 50 Bays. & 24,7 & 80,9 & 49,2 & $51,6 \mathrm{a}$ \\
\hline & $15 \mathrm{~B}+20 \mathrm{~T}$ & 20,9 & 76,1 & 38,9 & $45,3 \mathrm{ab}$ \\
\hline Média & & 21,2 & 73,4 & 43,9 & $46,2 \mathrm{a}$ \\
\hline \multirow{3}{*}{$\begin{array}{l}\mathrm{DH}=30 \mathrm{~d} \\
(\text { setembro) }\end{array}$} & S/Granul. & 16,6 & 60,4 & 33,4 & $36,8 \mathrm{~cd}$ \\
\hline & 50 Bays. & 19,9 & 76,1 & 36,1 & $44,0 \mathrm{ab}$ \\
\hline & $15 \mathrm{~B}+20 \mathrm{~T}$ & 19,9 & 60,4 & 32,7 & $37,7 \mathrm{~cd}$ \\
\hline Média & & 18,8 & 65,6 & 34,1 & $39,5 b$ \\
\hline \multirow{3}{*}{$\begin{array}{l}\mathrm{DH}=60 \mathrm{~d} \\
\text { (ago-set) }\end{array}$} & S/Granul. & 18,5 & 50,9 & 30,0 & $33,1 d$ \\
\hline & 50 Bays. & 20,4 & 66,1 & 31,2 & $39,2 \mathrm{~cd}$ \\
\hline & $15 \mathrm{~B}+20 \mathrm{~T}$ & 19,5 & 68,5 & 29,8 & $39,3 \mathrm{~cd}$ \\
\hline Média & & 19,5 & 61,8 & 30,3 & $37,2 b$ \\
\hline \multirow{3}{*}{$\begin{array}{l}\mathrm{DH}=90 \mathrm{~d} \\
\text { (jul-set) }\end{array}$} & S/Granul. & 16,6 & 39,7 & 28,0 & $28,1 \mathrm{~d}$ \\
\hline & 50 Bays. & 18,0 & 49,0 & 33,5 & $33,5 \mathrm{~d}$ \\
\hline & $15 \mathrm{~B}+20 \mathrm{~T}$ & 14,7 & 41,4 & 30,8 & $29,0 \mathrm{~d}$ \\
\hline Média & & 16,4 & 43,4 & 30,8 & $30,2 \mathrm{c}$ \\
\hline \multirow{3}{*}{$\begin{array}{l}\mathrm{DH}=120 \mathrm{~d} \\
\text { (jun-set) }\end{array}$} & S/Granul. & 18,5 & 37,6 & 30,1 & $28,7 \mathrm{~d}$ \\
\hline & 50 Bays. & 14,3 & 45,9 & 32,8 & $31,0 \mathrm{~d}$ \\
\hline & $15 \mathrm{~B}+20 \mathrm{~T}$ & 21,3 & 40,2 & 32,7 & $31,4 d$ \\
\hline Média & & 18,0 & 41,2 & 31,9 & $30,4 \mathrm{c}$ \\
\hline \multirow{3}{*}{$\begin{array}{l}\mathrm{DH}=150 \mathrm{~d} \\
\text { (mai-set) }\end{array}$} & S/Granul. & 29,7 & 34,7 & 31,3 & $31,9 d$ \\
\hline & 50 Bays. & 14,3 & 38,1 & 29,8 & $27,4 \mathrm{c}$ \\
\hline & $15 \mathrm{~B}+20 \mathrm{~T}$ & 21,3 & 40,2 & 30,7 & $30,7 d$ \\
\hline Média & & 21,8 & 37,7 & 30,6 & $30,0 \mathrm{c}$ \\
\hline \multirow{3}{*}{$\begin{array}{l}\mathrm{DH}=180 \\
\text { (abr-set) }\end{array}$} & S/Granul. & 19,7 & 33,1 & 28,9 & $27,2 \mathrm{~d}$ \\
\hline & 50 Bays. & 21,2 & 35,0 & 30,1 & $28,8 d$ \\
\hline & $15 \mathrm{~B}+20 \mathrm{~T}$ & 18,9 & 39,0 & 29,7 & $29,2 d$ \\
\hline Média & & 19,9 & 35,7 & 29,6 & $28,4 \mathrm{c}$ \\
\hline \multirow{3}{*}{$\begin{array}{l}\mathrm{DH}=180 \\
\text { (out-mar) }\end{array}$} & S/Granul. & 15,7 & 42,8 & 40,2 & $32,9 \mathrm{~d}$ \\
\hline & 50 Bays. & 24,2 & 64,7 & 39,7 & $42,9 c$ \\
\hline & $15 \mathrm{~B}+20 \mathrm{~T}$ & 26,6 & 57,1 & 39,0 & $40,9 \mathrm{c}$ \\
\hline Média & & 22,2 & 54,9 & 39,6 & $38,9 b$ \\
\hline
\end{tabular}

政 $29,16 \%$

Os resultados obtidos, em termos de produção em sacas beneficiadas por hectare, podem ser vistos na Tabela 5 e na Figura 1. Analisando-se a Figura 1, verifica-se que, independentemente do uso de granulados, a melhor resposta, em termos de produção, foi a do tratamento sem déficit hídrico (irrigação todo o ano) com aumento de $101 \%$ quando comparado com testemunha não irrigada, resultados similares aos obtidos por Fernandes et al. (1998). Este tratamento foi superior estatisticamente a todos os outros, destacando-se em seguida, positivamente, em termos de produção, os tratamentos com
$\mathrm{DH}=30$ dias (setembro); $\mathrm{DH}=60$ dias (agosto e setembro) e DH no período chuvoso (outubro a março) cujas médias não diferiram significativamente a nível de $5 \%$ de probabilidade.

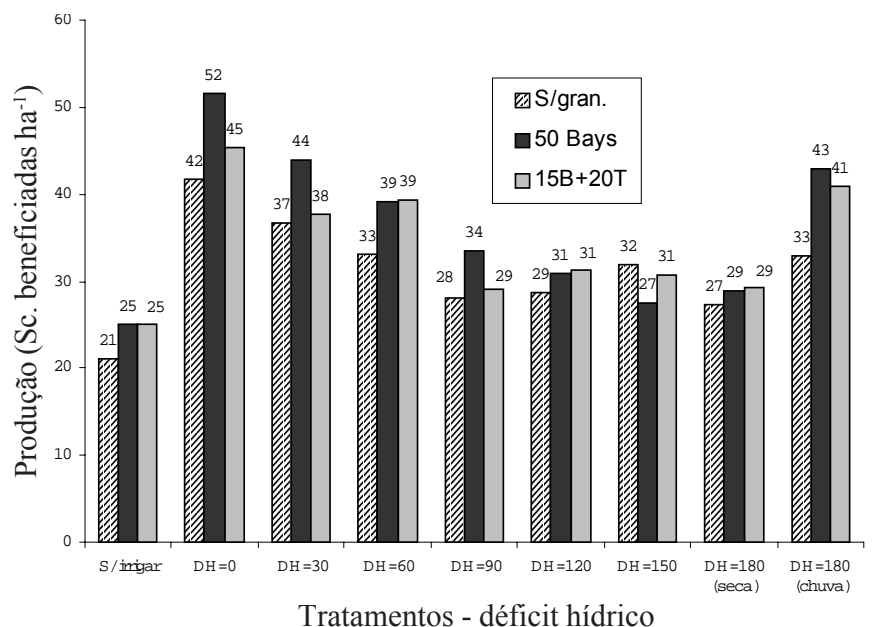

Figura 1. Produção média, em sacas beneficiadas por hectare de café variedade Mundo Novo 379/19, submetido a diferentes tratamentos de deficiência hídrica e uso de granulados no solo, em 1995, 1996 e 1997

Os tratamentos $\mathrm{DH}=90$ (interrupção da irrigação no período de julho a setembro), $\mathrm{DH}=120$ (período de junho a setembro sem irrigação) e $\mathrm{DH}=120$ (de maio a setembro sem irrigação) não diferiram significativamente e proporcionaram produções médias na faixa de 30 sacas beneficiadas por hectare. O tratamento referente ao déficit de 180 dias na seca (de abril a setembro) ocupou o $5^{\circ}$ lugar em termos de produção média, e o tratamento com DH total (sem irrigação) foi considerado estatisticamente o pior, em termos de produção (Tabela 5).

A supressão da irrigação por 30 e 60 dias reduz a produção em relação ao tratamento sem déficit, em 29 e $38 \%$, respectivamente. Os longos períodos de déficit $(60,90,120 \mathrm{e}$ 180 dias) reduzem a produção em cerca de $70 \%$.

Comparando-se o tratamento sem déficit hídrico com o tratamento com déficit apenas na época das chuvas $(\mathrm{DH}-180$ dias, de outubro a março) verificou-se redução de produção de cerca de 6 sacas de café beneficiadas por hectare no tratamento com déficit, o que pode ser explicado pela ocorrência de veranicos e pela má distribuição das chuvas no período de outubro a março (Figura 1).

Comparando-se os tratamentos com maior déficit $(\mathrm{DH}=180$ dias, na época das chuvas e da seca) constatou-se redução de produção de 10 sacas beneficiadas por hectare, em média, no tratamento com déficit na seca, em comparação com o tratamento com interrupção das regas na época das chuvas, ressaltando-se a importância da irrigação na época de maior deficiência hídrica na região (julho a setembro). A supressão da irrigação por $30 \mathrm{e}$ 60 dias reduz a produção em relação ao tratamento sem déficit, em 29 e 38\%, respectivamente. Os longos períodos de déficit $(60,90,120$ e 180 dias) reduzem a produção em cerca de $70 \%$ (Tabela 5).

Com relação aos granulados, verificou-se superioridade da associação Triadimenol + Dissulfoton aplicado na dosagem de $50 \mathrm{~kg} \mathrm{ha}^{-1} \mathrm{ano}^{-1}$, principalmente nos tratamentos de menor déficit hídrico $(\mathrm{DH}=0, \mathrm{DH}=30$ e $\mathrm{DH}=60$ dias $)$, similar ao que foi 
obtido por Fernandes et al. (1998) que, após 3 safras conduzidas em Bonfinópolis, MG, verificaram maior eficiência da associação Triadimenol + Dissulfoton na dosagem de $50 \mathrm{~kg} \mathrm{ha}^{-1}$ ano $^{-1}$, com aumentos de produção de 37 a $66 \%$ em relação à testemunha, independentemente do manejo de irrigação adotado. Barros et al. (1999) e Matiello et al. (1999) também obtiveram resultados positivos na aplicação desses produtos, em relação à testemunha onde não foram aplicados produtos granulados.

Não foram constatadas diferenças significativas entre as médias de produção obtidas com os três produtos granulados, para os tratamentos com DH $=90, \mathrm{DH}=120 \mathrm{e} \mathrm{DH}=180$ dias (na época das secas).

A eficiência dos produtos granulados dentro de um mesmo tratamento de irrigação, foi sempre maior quanto menores foram os períodos de déficit hídrico, o que permite concluir-se que a umidade do solo está intimamente ligada à eficiência da utilização de produtos granulados (Tabela 5). Em geral, os tratamentos sem aplicação de produtos granulados tiveram produções menores comparadas às parcelas em que esses produtos foram aplicados, exceção feita ao tratamento $\mathrm{DH}=150$ dias, cujas parcelas que não receberam produtos granulados apresentaram maiores médias de produção, dentro do mesmo tratamento de irrigação. Analisando-se a interação irrigação e granulados, verifica-se superioridade estatística, a nível de 5\% de probabilidade pelo teste de Tukey do tratamento irrigação total e produtos Triadimenol + Dissulfoton, em relação dos demais.

A aplicação de Triadimenol + Dissulfoton na dosagem de $50 \mathrm{~kg} \mathrm{ha}^{-1} \mathrm{ano}^{-1}$, proporcionou aumentos na produção, de 5\% $(\mathrm{DH}=180$ dias, na seca $)$ a $24 \%(\mathrm{DH}=180$ dias, nas chuvas $)$ comparado aos tratamentos sem a utilização de produtos granulados. No tratamento $\mathrm{DH}=150$ dias, houve redução de cerca de $16 \%$ quando o produto foi aplicado, em relação às parcelas sem granulados.

\section{CONCLUSÕES}

Com os resultados obtidos nos 3 anos de ensaio, conclui-se que:

1. A irrigação anual (janeiro a dezembro) proporcionou a maior produtividade, com acréscimos de mais de $100 \%$ em relação à testemunha não irrigada.

2. A supressão da irrigação no período chuvoso provocou redução de até $32 \%$ na produção, devido à incidência de veranicos e má distribuição de chuvas.

3. A associação Triadimenol + Dissulfoton no solo foi mais eficiente, com aumentos de produção de 5 a $24 \%$.

\section{REFERÊNCIAS BIBLIOGRÁFICAS}

ARAÚJO, J.A.C. Análise do comportamento de uma população de café Icatu sob condições de irrigação por gotejamento e quebra-vento artificial. Piracicaba: 1982. 87p. ESASLQ/USP. Dissertação Mestrado

BARRETO, G.B.; REIS, A.J.; DEMATTÊ, B.J.; IGUE, T. Experiência de irrigação e modo de formação de café novo. Bragantia, Campinas, v.31, n.4, p.41-50, 1972.

BARROS, U.B.; BARBOSA, C.M.; MENDONÇA, G.; MATIELLI, A.; FREITAS, J. L. P. Evolução da produção do cafeeiro devido ao efeito do uso de Baysiston por vários anos consecutivos. In: CONGRESSO BRASILEIRO DE PESQUISAS CAFEEIRAS, 25, 1999, Franca, SP, Anais... Franca, MAA/PROCAFÉ, 1999. p.222-223.
CAMARGO, A.P. de. Balanço hídrico, florescimento e necessidade de água para o cafeeiro. In: SIMPÓSIO SOBRE O MANEJO DE ÁGUA NA AGRICULTURA, Campinas: Fundação Cargill, 1987. p.53-90.

CAMARGO, A.P. de. Prescrição de regas para cafezal em áreas de seca prolongada de inverno. In: CONGRESSO BRASILEIRO DE PESQUISAS CAFEEIRAS, Maringá. Anais..., 1989. p.65-70.

CAMARGO, A.P.; CAMARGO, M.B.P. de. Estimativa da evapotranspiração potencial utilizando-se dados de temperatura do ar. In: CONGRESSO BRASILEIRO DE AGROMETEOROLOGIA, III, Anais... 1983.p.229-244.

COMPÊNDIO DE DEFENSIVOS AGRÍCOLAS: Guia prático de produtos fitossanitários para uso agrícola, 3. ed. São Paulo: Editora Andrei Ltda., 1990. 478p.

FERNANDES, A.L.T.; SANTINATO, R.; DRUMOND, L.C.; LESSI, R.; OLIVEIRA, M. Efeito da utilização de granulados de solo (Baysiston, Bayfidan e Temik) na produção de cafeeiros irrigados por gotejamento com 4 níveis de irrigação. In: SIMPÓSIOBRASILEIRODEPESQUISAEMCAFEICULTURA IRRIGADA, 1, Araguari, MG, Anais....1998. p.45-48.

GOMIDE, R.L. Monitoramento para manejo da irrigação: Instrumentação, automação e métodos. In: FARIA, M.A. de; SILVA, E.L. da; VILELA, L.A.A.; SILVA, A.M. da (eds) Manejo da Irrigação. Lavras, UFLA/SBEA, 1998. p.133-238. MATIELLO, J.B.; BARROS, U.V.; BARBOSA, C.M. Parâmetros de crescimento em cafeeiros submetidos a longos períodos de tratamento com fungicida-inseticida granulado de solo. In: CONGRESSO BRASILEIRO DE PESQUISAS CAFEEIRAS, 25, 1999, Franca, SP, Anais..., MAA/PROCAFÉ, 1999. p.11-12.

MATIELLO, J.B.; DANTAS, F.S. Desenvolvimento do cafeeiro e seu sistema radicular, com e sem irrigação, em Brejão, PE. In: CONGRESSO BRASILEIRO DE PESQUISAS CAFEEIRAS, Campinas, SP. Anais..., MAA/PROCAFÉ, 1987. p.165-166.

NJOROGE, J.M. A review of some agronomic investigations on arabica coffee in Kenya. Kenya Coffee, Nairobi, v.54, n.629, p.553-567, 1989.

PEREIRA, A.R.; VILLA NOVA, N.A.; SEDIYAMA, G.C. Evapo(transpi)ração. Piracicaba, SP: FEALQ/ESALQ-USP, 1997. 183p.

REIS, G.N.; MIGUEL, A.E.; OLIVEIRA, J.A. Efeito da irrigação, em presença e ausência da adubação NPK, em cafeeiros em produção - Resultados de 3 produções - em Caratinga - MG. In: CONGRESSO BRASILEIRO DE PESQUISAS CAFEEIRAS, Espírito Santo do Pinhal, SP, Anais..., MAA/ PROCAFÉ, 1990. p.19-21.

SANTINATO, R.; FERNANDES, A.L.T.; FERNANDES, D.R. Irrigação na cultura do café. 1. ed. Arbore, 146p., 1996.

THORNTHWAITE, C.W. A re-examination of the concept and measurement of potential evapotranspiration. Publications in climatology, John Hopkins University, v.7, n.1, p.200-209, 1954.

ZANINI, J.R.; OLIVEIRA, J.C.; PAVANI, L.C.; PEDROSO, P.A.; VALIM, M.R. Efeito da irrigação no desenvolvimento vegetativo de cafeeiros novos. In: CONGRESSO BRASILEIRO DE ENGENHARIA AGRÍCOLA, SBEA. Campinas, SP, Anais...., 1994. p.30. 